\title{
Comunidad Y Desarrollo En Los Andes Peruanos: Una Crítica Etnográfica AI Programa De Modernidad/Colonialidad
}

\section{Resumen}

En las últimas décadas la desconstrucción del desarrollo, conocida como el 'postdesarrollismo', ha cobrado gran auge en las ciencias sociales. En Latinoamérica el programa teórico denominado modernidad/colonialidad/descolonialidad (MCD) se propone descolonizar el pensamiento moderno re-escribiendo la historia global a partir de la experiencia colonial. Arturo Escobar, uno de los mayores teóricos del paradigma postdevelopmentalista se apoya en el proyecto MCD para pensar 'alternativas a la modernidad' (o transmodernidad). En este artículo propongo someter la perspectiva postdesarrollista y el proyecto MCD a un test etnográfico. Para eso me centro en las visiones y experiencias de Usibamba, una comunidad en los Andes Centrales Peruanos. La etnografía gira alrededor de la siguiente pregunta: iporqué los usibambinos, a pesar de todas sus experiencias negativas con el aparato del desarrollo, insisten en reivindicar la promesa del desarrollo? El programa de MCD nos permite entender el impasse de la comunidad en Usibamba? ¿Conceptos como pluriverso y transmodernidad nos permiten entender los deseos y aspiraciones de los usibambinos? Para responder a estas preguntas me apoyo en un análisis Žižekian que distingue entre 'lo actual', 'lo virtual', y lo 'Real' de la comunidad.

Palabras clave: Postdesarrollismo. Modernidad/Colonialidad/Descolonialidad. Desarrollo comunitario. Transmodernidad.

\footnotetext{
* Prof. Associado do Departamento de Sociologia do Desenvolvimento Rural na Universidade de Wageningen (Holanda).E-mail: pieter.devries@wur.nl
} 


\section{Community and Development in the Peruvian Andes: An ethnographic criticism to the modernity / coloniality research program}

\section{Abstract}

In the last decades the deconstruction of development, also known as 'postdevelopmentalism', has grown in popularity within social sciences. In Latin America, the theoretical program called Modernity/Coloniality/Decoloniality (MCD) aims at decolonizing the modern thought by re-writing global history from the perspective of local histories. Arturo Escobar, one of the main theorists of the postdevelopment paradigm, has adopted the MCD project in order to think about 'alternatives to modernity' (or trans-modernity). In this article I propose to submit the post-development and MCD programs to an empirical test. To that effect I centre on the visions and experiences of Usibamba, a community in the Central Andes of Peru. The ethnography is focused on the following question: why do usibambinos, in spite of all their negative experiences with the development apparatus, still insist on the promise of development? Does the MCD program enable us to understand the current impasse of community in Usibamba? Do concepts such as pluriverse and transmodernity enable us to understand the desires and aspirations of usibambinos? In order to respond to these queries I build upon a Žižekian analysis that distinguishes between 'the actual', 'the virtual', and 'the Real' of community.

Keywords: Postdevelopmentalism. Modernity/Coloniality/Decoloniality. Community development. Transmodernity.

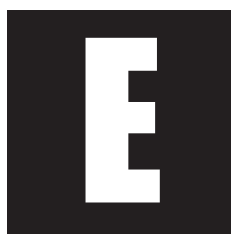

n las últimas décadas, hemos visto el auge de dos enfoques críticos importantes en Latinoamérica que se proponen 'desconstruir' el pensamiento eurocéntrico: la crítica al desarrollo denominada 'postdesarrollismo' y el programa teórico de modernidad/colonialidad/descolonialidad.

El enfoque postdesarrollista es una crítica basada en el post-estructuralismo, fuertemente influenciada por el pensamiento de Michel Foucault, 
un filósofo francés que en sus escritos nunca mostró mucho interés en la realidad (post)-colonial. El enfoque de modernidad/colonialidad/descolonialidad (MCD) es más radical en este sentido, ya que se propone 'desconstruir' la modernidad occidental desde la perspectiva del sujeto postcolonial. La pregunta que se plantea el primer enfoque es: a partir de qué relaciones de poder-conocimiento se construyen categorías cómo Tercer Mundo, pobreza, campesinado, género, etc. como objetos de intervención y análisis, al tiempo que se producen sujetos que son interpelados como carentes de desarrollo, es decir, sujetos subdesarrollados. El programa MCD se plantea la pregunta de cómo superar la condición postcolonial, es decir, 'decolonizar' las categorías de pensamiento imperantes, no solamente a través de la crítica epistémica (lo que correspondería con la agenda post-estructuralista), pero también re-descubriendo lo que la modernidad siempre se ha esforzado en ocultar: los saberes y experiencias 'no-modernos' que nunca han dejado de existir y reproducirse a la sombra de la modernidad.

En este artículo, propongo someter la perspectiva postdesarrollista y el programa de MDC a un test etnográfico. A partir de las visiones y experiencias de una comunidad de los Andes Centrales Peruanos, Usibamba, hago las siguientes preguntas: ¿por qué los usibambinos, a pesar de todas sus experiencias negativas con el aparato del desarrollo, insisten en reivindicar 'el desarrollo', o lo que ellos llaman 'las obritas'? Esta primera pregunta me conduce a la segunda: el programa de MCD realmente nos permite entender la condición postcolonial desde la perspectiva histórica de los usibambinos? Para responder a estas preguntas me centro en el trabajo de Arturo Escobar, quien ha sido un autor central en la crítica del desarrollo, proponiendo la búsqueda de 'alternativas al desarrollo', en contraposición al tema de desarrollo alternativo. En sus últimos trabajos, Escobar $(2008,2010)$ se apoya en el programa de MDC para hacer más explícita su propuesta postdesarrollista. 
El artículo se compone de tres partes. En la primera hago un breve resumen de las propuestas de Escobar enfocando en sus trabajos más recientes. La segunda parte es más extensa y trata de la comunidad andina de Usibamba. Los usibambinos exigen del estado y del aparato del desarrollo que les den lo que les han prometido: el desarrollo. Para ellos, el desarrollo tiene un lado utópico que les permite resolver los problemas que conlleva vivir en comunidad. Allí hago una distinción entre la 'realidad cotidiana' (lo actual) de la comunidad, la comunidad como un espacio 'virtual' que representa deseos de justicia e igualdad (lo virtual de la comunidad), y la comunidad como una entidad (ant)agónica y dividida que se reinventa milagrosamente mediante eventos fundacionales, lo que denomino lo 'Real de la comunidad' (es decir la imposibilidad constitutiva de la comunidad). En la tercera parte, respondo a la pregunta sobre la pertinencia del programa MCD para entender las visiones, deseos y expectativas de los usibambinos.

\section{Postdesarrollismo y el programa de MCD}

La crítica del desarrollo desde la perspectiva post-estructuralista (el postdesarrollismo) comprende los siguientes componentes:

1. El discurso del desarrollo fue construido dentro de un contexto político determinado (la guerra fría después de la Segunda Guerra Mundial) y dio lugar a la construcción de un aparato de poder-conocimiento que construyó tanto el objeto de desarrollo (el conocimiento sobre el subdesarrollo), como un sujeto subdesarrollado, caracterizado por toda suerte de carencias (de capital, conocimiento, nociones de progreso, etc.).

2. Vivimos en una era en que el discurso del desarrollo ha perdido toda legitimidad. Al cabo de seis décadas de desarrollo existe más 
pobreza, degradación ambiental y conflictos armados en el mundo que nunca. La noción misma de progreso está siendo ampliamente cuestionada, incluso dentro de amplios sectores en el aparato del desarrollo. Eso ha llevado a la búsqueda de modalidades de desarrollo que puedan atenuar sus potencialidades adversas (desarrollo humano, participativo, ecológico, etc.).

3. La actual coyuntura nos permite imaginarnos una era 'más allá del desarrollo' en la que el aparato del desarrollo deja de ser hegemónico. Vemos la irrupción de nuevas formas de organización no jerárquicas con características de redes (los movimientos sociales) con participación de una gran diversidad de actores y en las cuales las reivindicaciones culturales juegan un papel central.

Lo anterior, según Escobar, significa que movimientos sociales (pero también los planificadores y los académicos) tienen que tomar cuenta de tres procesos, cada cual con su programa político:

Desarrollo alternativo. Dentro de este esquema entrarían las propuestas actuales del aparato del desarrollo, lideradas por el Banco Mundial, que han adoptado temas como desarrollo humano, participación, biodiversidad y sustentabilidad ecológica. Con toda su capacidad de renovación, el aparato del desarrollo se fundamenta en una concepción eurocéntrica de la modernidad, como un evento histórico que inicia en Europa en el siglo XVIII y que se expande por todo el mundo. El desarrollo es la vía por la cual se debe realizar este proceso y, la globalización, su última fase histórica. Esta concepción de desarrollo, como proceso global orientado hacia la consecución de la modernidad, se expresa en el uso de indicadores globales de crecimiento, calidad de vida, paridad de género, etc. El programa político del desarrollo alternativo es claro: completar la modernidad como un proyecto universal con principios y valores como derechos humanos, concepciones del individuo, na- 
turaleza, democracia, progreso y bienestar, que tienen como origen la experiencia europea.

Las Modernidades alternativas representan formas de concebir el desarrollo desde una perspectiva no-Eurocéntrica, es decir, tomando en cuenta la existencia de distintas genealogías de construcción de modernidades alternas o múltiples. La noción de modernidades alternativas se fundamenta en una lectura histórica no-eurocéntrica de la modernidad, en la que esta se constituye a partir de la creación de un sistema mundo en el siglo XVI, después de la conquista de América (Wallerstein, 1974). La modernidad Europea, dentro de este esquema, es un proyecto hegemónico global con pretensiones universalistas. En la célebre frase de Mignolo (2000), se trata de un diseño global que deriva de una historia local (la Europea). Por tanto, es posible discernir diferentes formas de ser moderno en distintos contextos geopolíticos (una modernidad africana, andina o japonesa) y diferentes genealogías de construcción de modernidades. Ese planteamiento ha sido retomado dentro de la sociología del desarrollo por Arce y Long (2000) quienes argumentan que las modernidades múltiples se construyen como respuesta a los diseños globales del aparato del desarrollo. Toda intervención de desarrollo produce una contra-labor (counterwork en inglés) que se apropia de, recompone e hibridiza el diseño original y que alimenta una multiplicidad de modernidades alternas. El programa político del enfoque de modernidades alternativas es pluralizar las opciones de cambio, demostrar que no solamente las alternativas son posibles, sino que ya existen. Lo que falta es saber verlas (de Souza Santos s.d.).

Las alternativas a la modernidad, o la transmodernidad, son una radicalización del concepto de modernidades alternativas, desde una perspectiva ontológica. Los teóricos de la teoría de MCD proponen que la colonialidad es la otra cara de la modernidad y que la ideología de la 
visión única, uni-versal, de la modernidad es el eurocentrismo (Quijano en Escobar, 2008). La colonialidad, por lo tanto, invisibiliza, pero no logra deshacerse de los otros saberes que se propone destruir. Estos perviven y se reconstruyen al margen de la modernidad, en espacios que ya no son pre-modernos, pero que nunca fueron modernos. A diferencia de autores como Giddens, Habermas, pero también Hardt y Negri, que niegan la posibilidad de un punto de exterioridad al sistema global contemporáneo, Escobar argumenta que las alternativas al desarrollo pueden ser pensadas desde estos espacios ontológicos fuera de la modernidad. Estos otros espacios no solamente expresan otras formas de concebir lo real (es decir desde la epistemología), aún más, son otras formas de construir lo real. El universo que corresponde a la ideología eurocéntrica da lugar al pluriverso que abarca estas otras formas de construir lo real. Este es el giro ontológico que Escobar anuncia al apoyarse en el paradigma de MDC. La pregunta teórica que Escobar plantea es si es posible 'pensar y moverse más allá del capital como la forma dominante de la economía, la Euro-modernidad como la forma dominante de construir la vida socio-natural, y del estado como la forma dominante de institucionalizar lo social'. El programa político de este proceso se centra entonces en la posibilidad de visualizar una era postdesarrollista, postcapitalista y postliberal, en que el desarrollo no sea el principio central de organización de la vida social, el capital, el principio central de organizar la economía y, el liberalismo, el principio central de organizar la política (Escobar, 2010, p. 13). Sin embargo, eso no significa que el desarrollo, el capitalismo y el liberalismo dejarían de existir. Al contrario, en un mundo pluriverso estos se verían atravesados por una ontología relacional en la cual no existe una separación entre lo social, lo político y la naturaleza. La apuesta de Escobar es que los movimientos sociales, como los representantes de la transmodernidad 
(las alternativas para la modernidad), constituyen los espacios políticos en que se articula la lucha contra el proyecto modernizante neo-liberal estatal en Latinoamérica.

Este es un resumen extremamente sumario del giro ontológico en la teoría del postdesarrollo y del uso del programa de MCD para poder pensar las 'alternativas a la modernidad'. La transmodernidad requiere otra manera de pensar la política. No se trata solamente de desconstruir dicotomías modernas como sociedad-naturaleza, individuo-poder, sino también de construir una teoría política desde la diferencia, es decir una ontología política. Cabe señalar que Escobar privilegia nociones territoriales de comunidad y de sujeto comunitario en contraposición a la de estado o individuo.

A continuación presentaré el caso de la comunidad de Usibamba y la curiosa relación que los usibambinos mantienen con el aparato del desarrollo y con su propia comunidad.

\section{El caso de la comunidad de Usibamba}

Usibamba es una comunidad localizada a una altura de 3,800 metros en los Andes Centrales del Perú y forma parte de la región alta del valle del Mantaro. El poblado tiene 2.500 habitantes y abarca 3.649 hectáreas de tierra comunal. Fue reconocida como una comunidad indígena en 1939 y más tarde, en los años 60, como una comunidad campesina. La historia de la comunidad se caracteriza por la existencia de graves conflictos agrarios que derivaron en dos re-estructuraciones agrarias radicales: durante el gobierno de Belaúnde en 1960, cuando 804 hectáreas de comuneros ricos fueron confiscadas y redistribuidas entre comuneros pobres; y, en 1970, durante el régimen militar de Velasco Alvarado, cuando se realizó una distribución total de las tierras agrícolas. Fue también 
durante este régimen que las tierras de la hacienda pastoral de la Cerro de Pasco Mining Company fueron nacionalizadas, creándose la llamada Sociedad Agraria de interés Social (SAIS) Túpac Amaru. Usibamba es una de las 17 comunidades colindantes que fueron hechas socias propietarias de la SAIS. No podemos entender la posterior historia de la comunidad de Usibamba sin profundizar en el papel de la SAIS en la constitución de un nuevo orden regional.

La SAIS respondía a un modelo de modernización agraria impulsado por el régimen reformista militar. El sector campesino se vería beneficiado por la constitución de cooperativas comunales que recibirían apoyo tecnológico y financiero de la SAIS con el fin de modernizar el sistema pastoral y agrícola. Al mismo tiempo la SAIS ofrecía puestos de trabajo a las comunidades socias. Sin embargo, las comunidades socias, lideradas por Usibamba, nunca aceptaron el modelo corporativo de la SAIS, exigiendo la restitución de tierras que ellos alegaban habían sido usurpadas por las ex-haciendas. Esta lucha entre comunidades socias y la SAIS se agudizaría a fines de los años 1980, cuando el movimiento maoísta Sendero Luminoso declaró la guerra al estado peruano y se propuso terminar, con el fin de ganarse el apoyo de los comuneros en los Andes, con el sistema de las SAIS. Como siempre en la historia de los Andes, fueron los campesinos las víctimas de la guerra sucia entre Sendero Luminoso (SL) y el estado peruano. Muchas comunidades de la región se vieron forzadas a desplazarse hacia el valle del Mantaro. No así Usibamba, cuya asamblea comunal declaró que todos los que dejaran la comunidad perderían sus tierras. Sendero Luminoso realizó varias incursiones dentro de la SAIS, pasando por tierras de Usibamba. En una de esas incursiones sacrificaron a varias reses y obligaron a los usibambinos a llevarse la carne.

Usibamba fue acusada por el ejército y la SAIS de aliarse con los senderistas con el fin de apropiarse de las tierras. Durante la guerra sucia los 
senderistas asesinaron a varios funcionarios de la SAIS y un cierto número de comuneros fueron desaparecidos por el ejército. La derrota de Sendero no significó el fin del conflicto entre SAIS y comunidades socias ya que estas, bajo el liderazgo de Usibamba, cuestionaron los malos manejos financieros de la SAIS, así como su papel represivo durante el conflicto armado. En efecto, en los años 90 del siglo pasado, surgió una nueva generación de líderes comunales muy ambiciosos que, después de pasar los principales cargos comunales (incluyendo el de presidente comunal), irrumpen en la política regional. Usibamba es conocida como una comunidad combativa, con un alto grado de organización comunal, lo que se manifiesta en un claro dominio de la estructura comunal sobre todos los pobladores, tanto los comuneros como los no-comuneros. Este dominio es tan fuerte que algunos comuneros se describen a sí mismos como 'siervos de la comunidad'. El régimen de comunidad en Usibamba también se caracteriza por la existencia de distintas categorías de comuneros, cada una de ellas con distintos derechos y obligaciones. Más adelante veremos que esta imagen de Usibamba como una comunidad combativa, unida y disciplinada, no es correcta. Argumentaremos que esta es una representación ideológica de la comunidad y que la comunidad está atravesada por toda suerte de contradicciones. Pero, antes de eso, sería interesante interrogarnos que piensan los usibambinos sobre el desarrollo.

No cabe duda de que la lucha por la tierra es un elemento fundamental para entender las visiones sobre el desarrollo de los usibambinos. $\mathrm{Y}$, en efecto, los usibambinos tienen una imagen muy clara de lo que ellos entienden por desarrollo. Al preguntarles que entendían por desarrollo, ellos responden 'un extensionista que les enseñe a cultivar sus tierras' (de Vries, 2007). En breve, que les diga qué tipo de fertilizante y de plaguicida necesitan para aumentar el rendimiento de sus tierras. En esta visión no vemos simpatía alguna por alguna noción de desarrollo alternativo, y aún 
menos por la idea de 'alternativas para el desarrollo'. La preocupación de ellos es el acceso a la tierra y las condiciones para trabajarla. Se podría decir que lo que ellos quieren es desarrollo y punto.

Sin embargo, la verdad es que hace mucho tiempo que no llega un extensionista a Usibamba. La última vez que recibieron capacitación agrícola fue cuando estuvieron los técnicos de la misión alemana, en los años 1970, experiencia que recuerdan con gratitud. Los últimos años, después de la violencia que azotó la zona en los años 1980, empezaron a llegar ONG, pero estas les ofrecían otras cosas, como talleres participativos de género o de planeación estratégica, a cambio de ayuda alimentaria y otros servicios. Los Usibambinos sin embargo nunca se prestaron para participar en actividades que ellos no veían como conducentes a lo que ellos entendían por desarrollo. Es así que, a diferencia de otras comunidades, Usibamba nunca aceptó la entrada de ONG que les ofrecen talleres de desarrollo participativo y alternativo. En efecto, los usibambinos siempre insistieron en su deseo por el desarrollo, utilizando un lenguaje modernista que adoptaron del discurso de la reforma agraria en los años 1970. El desarrollo, en fin, para ellos, significa una promesa que les fue hecha y que no les llegó. Es por eso que, en sus relaciones con las agencias de desarrollo, insisten en lo que ellos llaman 'las obritas', las obras de riego, los caminos, las tecnologías, los insumos que les fueron prometidos y que no les llegaron.

A falta de proyectos de desarrollo que respondieran a sus expectativas, los usibambinos se volcaron a toda clase de iniciativas que para ellos significaban el progreso. Fue así que establecieron un colegio tecnológico y que empezaron a invertir en la instalación de un sistema de internet. Desde hace dos décadas, un gran número de usibambinos (un 10\% de la población masculina) ha estado migrando a EEUU a trabajar como pastores en ranchos de ovejas. Desde entonces, la comunidad cuenta con una 
fuente adicional de recursos para actividades de desarrollo. El uso de los recursos, tanto naturales como financieros, está sujeto a una contabilidad muy estricta. La dirigencia comunal rinde cuentas todos los años de todo ingreso y todo gasto. Lo mismo sucede con las tierras que son devueltas para la comunidad para fines de redistribución, para lo cual existen libros especiales Ilamados diccionarios de tierras (Nuijten y Lorenzo, 2009b). Debido a las frecuentes acusaciones contra los dirigentes de la comunidad de que abusan de su poder para beneficiarse a sí mismos o a sus familiares, la duración de las administraciones comunales (presidencia, secretario y fiscales) ha sido recortada a un año. Esto significa que al final del año toda administración tendrá que rendir cuentas ante la asamblea comunal, y estará sujeta a juicio por la próxima dirigencia.

¿Cómo entender entonces este deseo por el desarrollo que a primera vista parece ser excesivamente modernista? Sería ingenuo asumir que los usibambinos no son conscientes de las consecuencias nefastas que los proyectos de desarrollo pudieran tener para sus vidas (riesgos ecológicos, conflictos inter e intra-comunales por el acceso a los nuevos recursos). Ellos también son muy conscientes de los riesgos de relacionarse con actores externos. De hecho, el desarrollo ha significado para ellos establecer una relación conflictiva con un 'otro' (el estado peruano desarrollista), llena de tensiones, y muchas veces con un carácter muy violento.

En otro artículo (de Vries, 2007) propuse la idea de que el aparato de desarrollo funciona como una máquina que genera toda clase de deseos (por mercancías, salud, educación, sentimientos de pertenencia a la nación) que no son cumplidos, como una máquina de deseo que genera expectativas pero que no cumple con sus promesa. El modus operandi del aparato de desarrollo es el de generar y banalizar los deseos por el desarrollo. La promesa del desarrollo les fue presentada a los usibambinos a través de los programas de reforma agraria, que les prometían 
incluirlos dentro del proyecto nacional desarrollista mediante la constitución de cooperativas agrarias y la transferencia de tecnologías modernas. Los usibambinos rápidamente se dieron cuenta de que esta forma de incorporación institucional era una manera de no tener que concederles lo que para ellos era la exigencia principal para el desarrollo, las tierras monopolizadas por la ex-hacienda pastoral de la Cerro de Pasco Mining Company. En efecto, los usibambinos siempre siguieron insistiendo en proyectos productivos y en sus necesidades de tierra, oponiéndose al modelo burocrático-corporativista representado por la SAIS, un modelo que significaba la banalización de sus deseos por el desarrollo.

Los usibambinos no solamente están fascinados por las tecnologías modernas, sino también por los símbolos y los rituales disciplinarios del aparato burocrático-militar. Ellos se sienten orgullosos de ser peruanos, tanto así que cada asamblea comunal inicia con el canto del himno nacional. Las fiestas patrias son conmemoradas con entusiasmo, y se celebran con desfiles militares en los que participan escolares y colegiales en sus respectivos uniformes, y por comuneros y no-comuneros organizados por barrio, en atuendos hechos específicamente para la ocasión. En efecto, no solamente existe mucha admiración por la disciplina militar, sino también por las prácticas burocráticas de instituciones como el ministerio de agricultura o el catastro. Esto último se refleja en un sistema de registros de tierras y de entradas e ingresos financieros que, a primera vista, parece muy completo. Esta admiración e imitación de prácticas y rituales de estado pudiera parecer curiosa en una región donde el estado peruano tradicionalmente ha tenido muy poca presencia y, cuando la tuvo, lo fue por lo general a través de una fuerza militar. No vemos acá un rechazo del proyecto modernista del estado peruano, tampoco una relación de subordinación, sino más bien la imitación de un orden y una disciplina que ellos tratan de incorporar en el funcionamiento interno de la comunidad. 
Veremos que esta paradoja - la imitación de rituales de orden y disciplina del aparato estatal - es sintomática de la existencia de contradicciones profundas en el seno de la comunidad.

Los usibambinos no solamente rechazan las ONG y sus talleres participativos de desarrollo alternativo, sino que tampoco muestran alguna simpatía por el discurso 'Wanca' de los nuevos partidos indigenistas que han surgido en los centros urbanos de la región central del Perú. Según este discurso, la región Centro Andina se caracteriza por la existencia de una población de origen pre-incaico, perteneciente a la etnia Wanca, que siempre preservó su autenticidad cultural desde tiempos precolombinos. En este discurso, los Wankas son vistos como un pueblo orgulloso que nunca se sometió a un poder externo, ni a los incas, ni a los españoles. Incluso en tiempos republicanos, la resistencia a la invasión chilena por grupos armados locales (las famosas montoneras) habría sido inspirada por nociones de autonomía e independencia típicamente Wancas (Mallon, 1995). Los usibambinos definitivamente mantienen una consciencia histórica de la lucha contra los chilenos, pero sin adherirse a estas formas de nacionalismo regional tan en boga en Huancayo, la capital de la región. Sería también falso hablar de Usibamba como una comunidad tradicional que exhibe patrones precolombinos de cooperación andina. Al contrario, la comunidad en Usibamba es, y ha sido siempre, muy disputada y no pocas veces en los últimos años se ha discutido la posibilidad de quitarle atribuciones a la institución comunal, por ejemplo mediante la privatización de las tierras agrícolas (Gilvonio, 2009). Una pregunta clave, entonces, seria cómo entender la centralidad de la comunidad en las vidas de los usibambinos, hoy por hoy.

Usibamba es conocida en la región como una comunidad unida y disciplinada, única por sus prácticas anuales de redistribución de la tierra. En eso Usibamba es una excepción. En la región, la institución comunal 
experimenta una crisis de legitimidad. Una queja recurrente en algunos poblados en la zona es la pérdida de los valores y de las prácticas comunales. Comunidades aledañas han pasado por procesos de diferenciación socio-económica marcados, y la asamblea comunal ha perdido legitimidad. Los comuneros más pobres se quejan en estos poblados que la comunidad es monopolizada por una élite que mantiene buenas relaciones con comerciantes y políticos regionales. Otras comunidades han dejado virtualmente de existir. ¿Cómo entender, entonces, el vigor de la institución comunal en Usibamba?

Es importante destacar la importancia de la comunidad en la vida de los usibambinos. Es dentro de la comunidad que ellos adquieren un sentimiento de pertenencia. Es a través de la comunidad que pueden reclamar derechos al estado peruano, y que pueden incursionar en la política regional. La experiencia de vivir fuera de la comunidad es, para los usibambinos, extremamente frustrante en vista del racismo imperante en el Perú, o en los EEUU para el caso de los migrantes que trabajan en ranchos pastorales. Es a través de la comunidad que los usibambinos construyen nociones de persona. Un buen ejemplo de este sentimiento de pertenencia y construcción de persona a través de la comunidad es la activa participación de migrantes en EEUU en la política comunal. Sin embargo, la comunidad, como veremos, está profundamente dividida. Aun más, tendremos que concluir que la idea de solidaridad y consenso comunal es una ficción necesaria para los usibambinos. El argumento que queremos elaborar a continuación es que la persistencia de la comunidad se fundamenta en la facultad de desear el desarrollo. En otras palabras, para responder a la pregunta de por qué los usibambinos insisten en una promesa que siempre les fue incumplida y que solamente acarreó relaciones peligrosas con agentes externos, es importante conocer el significado histórico que la comunidad tiene para ellos. 
Como mencioné, la visión etno-indígena Wanca no existe entre los comuneros, sino entre intelectuales urbanos, muchos de ellos exmilitantes desencantados de partidos de izquierda, que dejaron de creer en un proyecto nacional de desarrollo y que se rebelan contra la modernidad occidental. ¿Por qué entonces esta ortodoxia ideológica en Usibamba, el no querer renunciar a la promesa del desarrollo y el rechazo a visiones de desarrollo alternativo propuestas por las ONG y por los políticos citadinos de Huancayo y otras ciudades andinas? Para responder a esta pregunta hay que tomar en cuenta que el desarrollo, como utopía, no solamente está basado en una noción del buen vivir, sino también, como señalamos arriba, en nociones de justicia social, y de conciencia histórica (Walsh, 2010). Se trata, en fin, del sinnúmero de batallas, muchas veces perdidas, que se libraron en el pasado contra gamonales, inversores extranjeros, y el aparato burocrático y militar del estado. Desear el desarrollo para ellos es una manera de revivir esas luchas, de seguir insistiendo en las promesas de una vida mejor, de ciudadanía, de progreso, que les hicieron y que no fueron cumplidas. Es precisamente esa insistencia en el deseo del desarrollo que insta a los usibambinos a seguir pensándose como una comunidad.

Como veremos más adelante, sería falso describir la comunidad como una institución armónica que representa los intereses de todos los comuneros. Existen contradicciones socio-económicas entre los usibambinos, tanto comuneros como no-comuneros. Muchos usibambinos migran a los Estados Unidos de Norte América y ganan fuertes sumas de dinero, adquieren mucho prestigio y, por lo tanto, la posibilidad de sustraerse a las reglas de la comunidad se ha incrementado. Estos cambios son vistos como una amenaza para la comunidad. La comunidad opera como una arena de luchas y de negociación en la que se discuten problemas relacionados con temas como la re-distribución de la tierra, la relación 
conflictiva con el estado, la financiación y participación en obras comunales y de desarrollo, etc. Pero la negociación se da dentro de un marco muy estricto de orden y disciplina comunal. El proyecto de comunidad en si no está sujeto a negociación.

Hay una paradoja entonces en la lealtad de los usibambinos hacia el concepto del desarrollo. Por un lado, ellos se sienten traicionados por las agencias desarrollistas del estado peruano y de cooperación internacional (el aparato del desarrollo) que los abandonaron cuando más las necesitaban. Por otro lado, el concepto de desarrollo les permite persistir en sus deseos de justicia social. En este sentido, los usibambinos toman el discurso del aparato del desarrollo muy en serio. En términos teóricos, podríamos decir que, a diferencia de los postdesarrollistas que se adhieren a una noción discursiva del lenguaje, los usibambinos son realistas, incluso literalistas en lo que se refiere al sentido del lenguaje. El desarrollo para ellos no es un aparato discursivo, sino una promesa que existe y que debe ser cumplida mediante obras de infraestructura, asistencia tecnológica, etc., y toda traición a esta promesa debe ser condenada. Para ellos, el desarrollo es uno, así como la modernidad o la globalización.

Pero, como señalé, el deseo por el desarrollo no se restringe a los objetos-causa de deseo (las obritas) que ellos reclaman. Estas evocan algo más grande, la (im)posibilidad de resolver la relación traumática con el estado y el aparato del desarrollo. Es la facultad mimética del deseo que le confiere un valor utópico al desarrollo. El objeto de desarrollo, por lo tanto, revela y al mismo tiempo encubre el deseo: revela la posibilidad del deseo y encubre la imposibilidad de alcanzarlo. En este sentido, los usibambinos son unos realistas-utópicos. Ya vimos que el deseo por el desarrollo es alimentado por la adopción de toda clase de rituales de estado, que funcionan como significantes de orden y disciplina. ¿No existe algo más contradictorio que adoptar los rituales de un aparato burocrático y 
militar el cual no solamente los ha traicionado sino que también los ha amenazado y violentado? ¿Cuál es entonces la lógica de persistir en un deseo que ha sido la causa de tantos sufrimientos? La única respuesta es que esta insistencia es un clamor por justicia social y por reparación histórica. En otras palabras, el desarrollo les permite a los usibambinos desear 'lo imposible'. Y, por extraño que parezca, este deseo de lo imposible es clave para la sobrevivencia de los usibambinos. Es precisamente la discrepancia entre la promesa utópica y la realidad decepcionante del desarrollo que les permite desear un futuro mejor. $Y$ sin esa facultad de desear el desarrollo, la comunidad, como veremos, estaría condenada. El desarrollo, como toda utopía, es tanto una imposibilidad - en caso contrario no sería una utopía - como una condición de posibilidad para el futuro de Usibamba como comunidad. Veremos que esta discrepancia produce toda clase de tensiones y conflictos que solamente pueden ser resueltos a través de la construcción de un régimen disciplinario comunal.

\subsection{El régimen disciplinario de la comunidad}

Como señalé, la imagen de Usibamba como una comunidad consensual y unida, donde existe una distribución equitativa de la tierra y poca diferenciación socio-económica no es correcta. Ya vimos que muchos comuneros que migran a EEUU acumulan sumas considerables de dinero que utilizan para construir casas y poner negocios (por lo general de transporte) en Usibamba o en otras localidades de los Andes Centrales. Más bien, lo que existe es un régimen disciplinario que hace toda clase de demandas a toda la población usibambina, sean estos comuneros o no, migrantes o no-migrantes, a cambio del derecho a acceder a recursos de la comunidad durante las redistribuciones anuales de la tierra. Más adelante veremos que la efectividad práctica de este régimen disciplinario no es muy grande. Como no hay suficiente tierra para repartir, la comu- 
nidad solamente puede imponerse radicalizando sus demandas, exigiendo de los comuneros y los no-comuneros una lealtad incondicional a la comunidad. Los usibambinos se quejan mucho de lo que ellos llaman 'la servidumbre comunal', pero no se rebelan contra ella. Efectivamente, los usibambinos pueden sentir orgullo de servir a una institución que en otros momentos ven como un ente autoritario y arbitrario.

Para entender esta situación contradictoria es importante destacar que ser comunero es un status que se adquiere a través de una muestra de compromiso con la comunidad, y que hay diferentes categorías de comuneros. Un comunero tiene que mostrar una fuerte dedicación a la comunidad a través de participación en faenas (obras comunales) y comités comunales (los cargos). De esa manera el comunero va construyendo 'un récord' que, a su vez, le da derecho a recibir tierras durante las redistribuciones anuales. Para los no-comuneros, siempre existe la opción de entrar en la comunidad, siempre y cuando demuestren las correspondientes aptitudes. Sustraerse a la hegemonía de la comunidad, sin embargo, es muy difícil, incluso para la categoría de 'no-comuneros'. Más adelante explicaremos porqué.

A continuación describiré a grandes rasgos las distintas categorías de comunero en términos de derechos y obligaciones diferenciados con respecto a la comunidad (Gilvonio 2009). De esa manera responderemos a la pregunta de cómo se sostiene el régimen disciplinario de la comunidad sobre las distintas categorías de comuneros.

Un comunero activo está obligado a seguir cargos, es decir se le exige una membresía activa en la comunidad (asambleas, faenas, cargos y responsabilidades oficiales). De esa manera, va acumulando un récord y gana derechos a la tierra. Los migrantes pueden seguir siendo comuneros activos, siempre y cuando paguen las multas. Los comuneros activos van acumulando un récord, es decir derechos a tierras hasta un máximo de 5 has. de riego y 12 has. de secano. 
Un comunero activo se jubila después de 25 años de servicio y obtiene el status de pasivo. Se le libera de la obligación de ocupar cargos pero tiene que devolver parte de sus tierras. En las asambleas comunales tiene derecho a participar en las discusiones pero no tiene derecho a voto.

Los no-comuneros o comuneros no-agrícolas son pobladores no comuneros. Por lo general son personas que no son originarias de Usibamba (es decir no son hijos de comuneros) y que no tienen interés en unirse a la comunidad por tener compromisos fuera de la comunidad (migración, carpintería, etc.). Los no-comuneros tienen derecho a una parcela urbana. Están obligados a participar en faenas y comités, pero con menor intensidad que en el caso de comuneros activos.

Como señalamos, durante los últimos años, han aumentado las quejas por las reglas cada vez más estrictas que la comunidad impone y el monto creciente de las multas. Para comenzar, existe la prohibición de vender en mercados de otros pueblos, y una obligación muy estricta de participar en faenas, y asociaciones. Incluso la participación en fiestas y desfiles en días festivos es obligatoria, so pena de multa. También se han estado aumentando las multas que los comuneros que migran a EEUU tienen que pagar a la comunidad por no participar en faenas, cargos, etc. Segundo, existen fuertes contradicciones entre comuneros jóvenes y viejos, activos y pasivos. Los viejos acusan a los jóvenes de ser perezosos y los jóvenes a los viejos de ser egoístas. Los jóvenes demandan reforzar el sistema de redistribución de tierra cuando un comunero se jubila o se muere. Los viejos ven en eso una negación de sus esfuerzos y de su derecho de dar la tierra en herencia a sus hijos (de Vries y Gilvonio 2001). Tercero, en los años 1990 aumentó fuertemente la migración de usibambinos a EEUU donde trabajan en ranchos como pastores de ovejas. Actualmente uno de cada 10 usibambinos varones está 'en el norte'. Los comuneros migrantes adquieren mucho pres- 
tigio gracias a su mayor poder adquisitivo como resultado de los ahorros en dólares que hicieron durante su estadía en ranchos pastorales en EEUU. Como respuesta a la fuerza económica de los migrantes que vuelven, la comunidad les demanda pruebas constantes de su lealtad, pidiéndoles que financien obras y fiestas comunales (Nuijten y Lorenzo 2009 a). Además la asamblea comunal ha decidido subir las cuotas que estos tienen que pagar para obtener el permiso de dejar la comunidad, y les impone toda clase de multas por su ausencia. Finalmente, existen contradicciones entre comuneros y no-comuneros (de Vries y Gilvonio 2001). Los no-comuneros se quejan de las humillaciones a las que son sometidos por la comunidad que les obliga a participar en faenas, sin concederles los derechos de participar en la toma de decisiones sobre proyectos que les conciernen (como construcción de caminos, el mercado, etc.).

En conclusión, la comunidad se encuentra en un impasse debido a su imposibilidad de responder a las demandas de tierra de los comuneros jóvenes y a la creciente diferenciación socio-económica causada en gran parte por la migración a EEUU. La respuesta de la asamblea comunal ha sido imponer reglas cada vez más estrictas, junto con la exigencia de una lealtad absoluta a la comunidad. Eso ha llevado a la constitución de un auténtico régimen disciplinario. Los comuneros se quejan de este régimen, pero al mismo tiempo están orgullosos de la fuerza de la comunidad y su capacidad de defenderse ante amenazas externas (el estado peruano, la SAIS, el poder de los migrantes). Si bien la comunidad es disputada, su legitimidad no es cuestionada, lo que se refleja en la autodenominación 'siervos de la comunidad'. A continuación veremos que ante la imposibilidad de implementar las reglas de la comunidad existe mucho espacio para negociación. La discrepancia entre la 'actualidad' de la comunidad y el deseo de orden y justicia comunal que la asamblea comunal transmite, ocasiona fuertes divisiones, no solamente a nivel comunal pero también a nivel individual. 


\subsection{Los tres registros de la comunidad}

Para entender esta discrepancia, o impasse, nos apoyamos en la distinción deleuziana entre los registros de lo actual, lo virtual y lo real, y en particular en la lectura lacaniana que Slavoj Žižek (2003) hace de esta distinción. 'Lo actual' de la comunidad se refiere a la 'realidad cruda' de la comunidad, que difiere marcadamente de la imagen sobre la comunidad que los comuneros proyectan, o la imagen que otros tienen de ella. Para comenzar, las multas que se imponen a los que infringen las reglas de la comunidad pueden ser muy altas pero finalmente siempre se puede negociar. Por lo general, el infractor paga según su capacidad de pago. Si bien todo hijo de comunero tiene derecho a la membrecía de la comunidad, y todo comunero desarrolla un récord que le permite acceder a más tierras, la práctica es que la asamblea adjudica la tierra que queda disponible por jubilación o muerte de un comunero a sus hijos. (Es por eso que los usibambinos dicen que no conocen un sistema de herencia, sino de preferencia). Por otro lado, no solamente existe mucho espacio de negociación, pero los registros de tierras no son completos. Es decir, no existe una correspondencia exacta entre los registros y la distribución de la tierra, lo que significa que muchas de las negociaciones que se hacen sobre papel encubren la existencia de relaciones de propiedad 'de facto' que se sustraen a la autoridad de la asamblea comunal (Nuijten y Lorenzo, 2009 b).

Lo que vemos, entonces, es un impasse de la comunidad que se refleja en la existencia de dos lógicas comunitarias. Por un lado, está la hegemonía de la comunidad como una institución regimentada y autoritaria que impone toda clase de reglas y multas y que responde a la demanda de orden y justicia de la colectividad de comuneros, y por otro lado la existencia de prácticas de negociación entre comuneros que siguen una lógica de alianzas familiares. Estas son dos lógicas opuestas de comunidad a las que los usibambinos se adhieren: la lógica de 'lo virtual' y la 
de lo 'actual'. Dentro de la lógica de 'lo virtual' exigen que la asamblea comunal imponga orden y haga valer su autoridad y critican las prácticas corruptas de comuneros que resuelven sus problemas en negociaciones al margen de la comunidad. Esta lógica, o registro, como lo llamaremos más adelante, representa el lado utópico de la comunidad: el deseo de igualdad y de justicia. Por otro lado, dentro del registro, o lógica, de lo 'actual, al verse enfrentados a la severidad de las decisiones de la asamblea, los comuneros recurren a las mismas prácticas de negociación que critican y que a su juicio subvierten la autoridad comunal. Esta lógica, o registro, corresponde con la 'actualidad' de la comunidad, es decir la posibilidad de negociar todas las reglas.

Este impasse se refleja en el mismo discurso de los comuneros que, por un lado, se quejan de que la comunidad los explota (lo actual) y, por otro lado, muestran orgullo en declarar que 'son siervos de la comunidad' (lo virtual). Este impasse apunta a lo que denominaremos 'lo real' de la comunidad, que representa un registro que trasciende tanto 'lo actual' (los intereses pragmáticos) de la comunidad y el dominio de posibilidad de la comunidad (lo virtual). En efecto, 'lo real' representa 'la imposibilidad constitutiva' de la comunidad: el hecho de que la ella solamente puede reproducirse radicalizándose y re-inventándose. Veremos más adelante que la reinvención de la comunidad acontece en eventos traumáticos como fueron las reestructuraciones totales de la tierra en tiempos pasados.

Es importante insistir en que el conflicto entre autoridad y negociación no se puede entender como una relación funcional, es decir, entre un discurso de autoridad y una serie de prácticas informales que permiten la reproducción (funcional) de la comunidad. Al contrario, acá nos encontramos ante dos lógicas comunales opuestas, cada una con su propio discurso y prácticas que producen contradicciones irresolubles en el seno de la comunidad. En otras palabras, la clave para entender la comunidad 
no es la discrepancia entre realidad e ideología, sino la existencia de conflictos que generan distintos discursos y prácticas (o realidades).

Pero antes nos plantearemos una pregunta clave para el análisis del impasse de la comunidad: ¿porqué los usibambinos siguen apostando por la comunidad? ¿No sería más fácil deshacerse de ella ante los conflictos que esta genera? Esta ha sido la respuesta de muchas comunidades en la región, que solamente existen de nombre. En efecto, los usibambinos se han visto enfrentados a esta posibilidad. Este fue el caso cuando el estado peruano les propuso un programa de privatización de tierras que les daría la facultad de dar en herencia sus tierras a sus hijos. Los pasivos respondieron con mucho entusiasmo ante esta opción, quejándose de la falta de compromiso de las nuevas generaciones de dirigentes comunales. Irónicamente los mismos comuneros que lucharon por la reestructuración total de la tierra durante la reforma agraria en 1973, como respuesta a la creciente diferenciación socio-económica, mostraron interés en un programa estatal que tenía como fin destruir los principios colectivos comunitarios por los que ellos lucharon. Vemos acá la contradicción entre el registro 'actual' de los intereses pragmáticos de los comuneros (en especial los mayores), y el registro 'virtual' de la posibilidad, es decir de la promesa de justicia y de igualdad.

La verdad es que estos programas de privatización de tierras, después de generar mucho entusiasmo, son rechazados por la asamblea comunal como una manera de 'dividir y desautorizar a la comunidad'. ¿Cómo entender entonces la centralidad de la comunidad para los usibambinos? Primero, como ya señalamos, la comunidad da un sentido de pertenencia a los usibambinos en un sistema globalizado que los margina. Segundo, la comunidad se compromete a dar tierras a todos los hijos de los comuneros, independientemente de la situación económica de sus padres. En este sentido la comunidad representa un deseo de justicia social profundo 
entre los usibambinos. Tercero, y este es un elemento fundamental para el análisis, 'la reinvención de la comunidad' es una respuesta a esta demanda de justicia social. Es decir, la comunidad se reinventa a través de eventos fundacionales - las redistribuciones totales - con efectos profundamente traumáticos. En otras palabras, la comunidad hay que entenderla como un síntoma que refleja traumas y contradicciones históricas que no han sido resueltos. Es este el registro de 'lo real' que expresa la contradicción fundamental de la comunidad y que la insta a radicalizarse.

A continuación definiremos los tres registros de comunidad y exploraremos sus consecuencias para entender cómo la comunidad produce 'sujetos de comunidad':

El registro de 'lo virtual', que corresponde a la promesa de solidaridad, de pertenencia y de justicia social. Este lado virtual de la comunidad se refleja en una insistencia en el deseo por el desarrollo a pesar de la traición del aparato del desarrollo. Este es el registro de la utopía.

El registro de 'lo actual': la 'actualidad' de la política cotidiana basada en los intereses pragmáticos familiares y que se refleja en las negociaciones en las cuales se adulteran las reglas que impone la asamblea comunal y que dan lugar a toda suerte de acusaciones sobre los 'malos manejos' de los dirigentes comunales.

El registro de 'lo real' de la comunidad: las contradicciones que subyacen a la 'imposibilidad constitutiva' de la comunidad, pero también la lealtad al evento fundacional o milagroso que dio nacimiento a la comunidad, como una promesa de justicia social.

De los tres registros el más enigmático es el tercero. 'Lo real' se manifiesta en las contradicciones entre 'lo virtual' y 'lo actual', que como señalamos, no puede ser visto como una relación funcional. Para comenzar, hay que insistir en que lo real no es la realidad, muy al contrario, 
corresponde a lo que no tiene cabida en la realidad, lo que la realidad no puede aceptar, o para ponerlo en términos coloquiales, lo que es 'más real' que la realidad. Dentro de la topología de 'lo virtual' y 'lo actual', 'lo real' se encuentra dentro de la intersección entre los primeros dos. Por un lado, 'lo real' corresponde a la imposibilidad de 'lo virtual', de la utopía', por otro lado apunta a la posibilidad de trascender la lógica utilitaria y pragmática de las negociaciones familiares ('lo actual') mediante la lealtad a la promesa y el deseo de solidaridad, justicia social y desarrollo. Se trata no simplemente de una serie de valores que no pueden ser realizados en la práctica, sino de una lealtad a un evento fundacional y traumático que convoca estos deseos.

Más adelante profundizaremos en este evento traumático, pero de momento quisiéramos mostrar cómo esta contradicción constitutiva construye un sujeto dividido, que oscila entre la lealtad a la promesa de justicia social y desarrollo y el seguimiento de sus intereses personales. Es esta división que produce un sujeto usibambino que puede estar orgulloso de servir a una autoridad y que, al mismo tiempo, se queja de las imposiciones de esta autoridad.

En términos lacanianos (Žižek, 2003) podemos hacer una distinción entre el sujeto del enunciado y el sujeto del enunciamiento. El sujeto del enunciado es el sujeto como se ve a sí mismo a través de los ojos del 'Otro', con mayúscula, el depositario de la autoridad, que en este caso sería la comunidad. El sujeto del enunciamiento denota al sujeto como este se ve a sí mismo a través del 'otro', con minúscula, es decir la relación inter-subjetiva con otras personas que, en este caso, serían los otros usibambinos, comuneros o no. El sujeto del Otro, en el caso de Usibamba, es el sujeto que se siente interpelado por una autoridad que le recuerda sus compromisos con la comunidad, que lo insta a ser leal a los principios de solidaridad. El sujeto del 'otro' es el sujeto que tiene el capital social 
para sacar provecho de situaciones imprevistas que se presentan en la comunidad, el sujeto pragmático que conoce sus intereses, que compite, negocia. La contradicción entre estas dos posiciones de subjetividad produce un sujeto dividido que oscila entre la lealtad a los deseos colectivos de la comunidad y la voluntad de defender sus intereses personales y de sentirse reconocido por su familia y otros comuneros.

En términos de la distinción que hicimos entre 'lo virtual', 'lo actual', y 'lo real', el sujeto del enunciado sería el sujeto virtual, el sujeto que cree en la utopía; y el sujeto del enunciamiento, el sujeto actual, el agente de la lógica de las prácticas sociales. ¿Cuál es entonces el sujeto de 'lo real'? El sujeto de 'lo real' corresponde al carácter dividido del individuo, lo que produce el 'dividuo', es decir, la imposibilidad del (in)dividuo de construir una subjetividad estable, homogénea. Es lo que antes Ilamamos la oscilación del individuo entre los deseos virtuales (p.e. por el desarrollo) y el conocimiento práctico de lo actual. Para ser precisos, el sujeto de lo Real se ubica en la intersección de dos posiciones de subjetividad, representadas por el sujeto del enunciado y el sujeto del enunciamiento. El sujeto de lo Real, por lo tanto, es el nombre de esa imposibilidad. Al mismo tiempo, hay que insistir en que el sujeto de lo Real tiene un fundamento muy 'real', en el sentido como señalamos de un evento traumático que es 'más real' que la misma realidad, tan 'real' que la realidad no la puede aceptar. La siguiente pregunta, entonces, es ¿̇cuál fue el evento traumático que constituye al sujeto de lo Real en Usibamba?

Para eso hay que ir atrás en la historia, al tiempo de la segunda reestructuración. Según los usibambinos, esta se hizo con el apoyo del estado. Pero la verdad es más compleja. Lo que ocurrió fue que se generó una alianza entre los sectores pobres de la comunidad y el ejército peruano contra los 'ricos' que fueron obligados a someterse a la nueva hegemonía de la comunidad a punta de pistola. Este evento atravesó las relaciones familiares 
que generaban lazos de unidad entre la categoría creciente de comuneros con poco acceso a la tierra, y la categoría de ricos que monopolizaba la mayor parte de la tierra. Este fue un evento sumamente traumático que los usibambinos evitan recordar, pero cuya memoria surge a veces cuando se emborrachan. Se trata entonces de una mentira pública, que no puede ser enunciada, pero que persigue a los usibambinos en sus pesadillas.

Slavoj Žižek (s.f.) caracteriza muy bien este evento llamado Comunidad cuando declara,

Ser miembro de la comunidad no es cuestión de identificarse sencillamente con una tradición simbólica explicita. Se llega a ser miembro solo cuando uno asume la dimensión espectral que sostiene a la tradición, los fantasmas muertos en vida que persiguen a los vivientes, la historia secreta de las fantasías traumáticas transmitidas 'entre las líneas', a través de los vacíos y las distorsiones de la tradición simbólica explícita. Žižek (s.f.)

Es esta historia oculta de la alianza de los pobres con el ejército peruano, el enemigo tradicional de toda comunidad andina, que constituye este gesto violento que hizo posible la reestructuración de la comunidad. Parafraseando a Žižek (s.f.), se podría decir que "la fidelidad a este Evento violento y fundacional es solamente posible al NO confesar, no simbolizar este evento: efectivamente, es este estatus 'reprimido', Real, del Evento que le da a la comunidad una vitalidad sin precedentes.

\section{Conclusión}

El caso de Usibamba da lugar a una reflexión crítica sobre la crítica post-estructuralista al desarrollo y la relevancia del programa de modernidad/colonialidad/descolonialidad (MCD). Para tal efecto, seguiré el esquema propuesto por Escobar para entender la relación de los usi- 
bambinos con el aparato del desarrollo. Antes de continuar, me gustaría hacer algunos comentarios metodológicos/teóricos sobre la construcción del estudio de caso de Usibamba. Es evidente que en el análisis del caso me apoyé en nociones teóricas específicas que no corresponden con la perspectiva de MCD. A mi parecer, eso no le quita relevancia al caso. En segundo lugar, la investigación no contempló el tema de la construcción de lo social y lo natural a partir de sus inter-relaciones, lo que no significa que este no hubiera surgido a lo largo de la pesquisa. Por esta razón tocaré el tema de las ontologías relacionales y pluriverso solamente de paso.

Empezaré con la distinción que Escobar hace entre desarrollo alternativo, modernidades alternativas y alternativas a la modernidad. Es evidente que los usibambinos no muestran ningún interés en el proceso de desarrollo alternativo. El desarrollo para ellos es un componente de la parte virtual de la comunidad, su lado utópico. Es decir el desarrollo no es visto simplemente como un instrumento para generar mejores condiciones de vida, sino como una promesa que se materializa en objetos de deseo, lo que los usibambinos Ilaman 'las obritas'. El principio de la promesa no cumplida del desarrollo no se negocia ni se trivializa, por tanto, el desarrollo no puede llevar un adjetivo.

La segunda pregunta es si los usibambinos estarían de acuerdo con la idea de que son parte de una modernidad alternativa. Para comenzar, la modernidad no es un concepto en uso por los usibambinos. Por otro lado, ellos saben que a los ojos del estado y de los mistis (mestizos) de la ciudad ellos son vistos como indígenas tradicionales, es decir, como nomodernos. En efecto, la existencia de una diferencia radical entre la vida en comunidad y fuera de la comunidad es algo que marca a los usibambinos. Ellos tienen una fascinación con las tecnologías más avanzadas, con los rituales del ejército peruano y las prácticas burocráticas de registro estatales y procuran imitarlos con el fin de fortalecer la comunidad.

Cómo señala Radomsky (2011), este sería un buen ejemplo de la dialéctica entre modernidad y (des)colonialidad, y de sus efectos en la cons- 
titución de modernidades alternativas. El uso de tecnologías y rituales de estado para crear zonas de autonomía en los que se (re)-constituyen saberes a la sombra de la modernidad hegemónica occidental pueden ser vistos como un ejemplo de insurgencia epistemológica que conduce a la construcción de una modernidad alternativa. Como señalé antes, no hicimos investigación a fondo sobre cómo los usibambinos viven la relación con la naturaleza. Sin embargo, sería interesante explorar la existencia de ontologías relacionales andinas para explicar relaciones y representaciones que no pueden ser explicados a partir de una racionalidad moderna-occidental. Es muy posible que conceptos como el pluriverso (en vez de universo) y de ontologías relacionales (en vez de ontologías dualistas) serian muy útiles para entender cómo los usibambinos construyen mundos socio-naturales que difieren radicalmente de representaciones binarias occidentales basados en nociones dualistas como sociedad-naturaleza, cuerpo-mente, espíritu-materia, etc. Sin embargo, y cómo demuestra la etnografía, hay buenas razones para suponer que tales ontologías relacionales no serían menos problemáticas para ellos que las ontologías dualistas para los modernistas occidentales. Efectivamente, la propuesta de entender la comunidad como una 'imposibilidad constitutiva' con sujetos divididos (o dividuos) apunta hacia una dimensión antagónica y traumática - lo que denominé 'lo Real dentro de la pluralidad de mundos ontológicos andinos.

El papel de la migración es sumamente interesante para responder a la pregunta de si los usibambinos son partícipes de una modernidad alternativa. Los usibambinos tienen una larga historia de migración a las ciudades, los valles y la selva en busca de trabajo. Además, desde los años noventa han estado migrando a los EEUU para trabajar en empresas ganaderas. Muchos migrantes regresan con dólares e invierten y fundan pequeñas empresas (por lo general de transporte) en la región (Gilvonio 2009). Sin embargo, los migrantes están supeditados a la autoridad de la comunidad. Muchos se quejan de que la comunidad los explota y algunos optan por cortar los lazos con la comunidad, pero no hay duda de que es la comunidad la que 
manda. La migración en Usibamba es una estrategia central, tanto para la sobrevivencia de las familias como para la comunidad. En conclusión, el caso de Usibamba puede ser visto como un ejemplo de una modernidad alternativa en razón de que los usibambinos, como muchos Andinos, se sienten excluidos de la modernidad occidental y por lo tanto recurren a la figura de la comunidad para construir sentimientos de pertenencia.

¿Podemos entender el caso de Usibamba como una posibilidad de visualizar la transmodernidad, o alternativa a la modernidad, en el sentido que Escobar le confiere; es decir como una era postdesarrollista, postcapitalista y postliberal, en el que el desarrollo no sea el principio central de organización de la vida social, el capital el principio central de organizar la economía y el liberalismo el principio central de organizar la política (Escobar 2010). La respuesta es negativa. Los usibambinos anhelan el desarrollo sin adjetivos, la promesa que no les fue concedida, en ese sentido son absolutamente desarrollistas. El desarrollo, repito, forma parte de la virtualidad de la comunidad y representa el compromiso con nociones de justicia e igualdad. Los usibambinos tienen una experiencia larga y conflictiva con el capitalismo y el estado. Las redistribuciones de la tierra han sido respuestas radicales a procesos de mercantilización de la tierra y para lograrlo han requerido entrar en alianzas con el estado. En los últimos años los usibambinos se han opuesto a los programa de titulación de la tierra en razón de que constituyen una amenaza para la comunidad y sus principios de igualdad y de justicia. Aunque Usibamba es considerado por muchos una comunidad modelo, comunista, en realidad dista mucho de serlo. La relación con el capital es contradictoria. Por un lado rechazan procesos de mercantilización capitalista como una amenaza a la comunidad, por otro lado la participación en circuitos de migración y trabajo asalariado en EEUU ha reforzado a la comunidad a través de los permisos pagados para migrar.

Escobar privilegia nociones territoriales de comunidad y de sujeto comunitario en contraposición a la de estado e individuo. El caso de Usi- 
bamba, sin embargo, es más complejo. Allí vemos tanto la existencia de sujetos comunitarios como de sujetos que se piensan como individuos, con intereses particulares. La comunidad se reproduce instaurando un orden disciplinario que opera, más que todo, al nivel de las apariencias. La relación de los usibambinos con la comunidad es paradójica, por un lado se auto-denominan con cierto orgullo siervos de la comunidad, legitimando de ese modo el régimen disciplinario, por otro lado son muy hábiles en usar la comunidad como una arena de negociaciones en la que prevalecen los intereses familiares. La comunidad, efectivamente aparenta funcionar como un estado, con todas las contradicciones que la noción de estado conlleva. Definitivamente, sería espurio tratar de entender el comportamiento de los usibambinos en términos de una lógica comunitaria-territorial opuesta a nociones liberales de individuo y estado. La comunidad, más allá de ser un ente representativo de la lógica comunitaria andina, funciona como una máquina generadora de síntomas que representan la contradicción entre nociones de solidaridad y de justicia y los intereses particulares de individuos y familias.

En efecto, la insistencia en el deseo por el desarrollo es fundamental para la sobrevivencia de la comunidad como una forma de organización social que da un sentido de pertenencia y que representa nociones de justicia social y de igualdad. Renunciar a la promesa del desarrollo significaría para ellos negar las luchas del pasado contra el latifundismo, el ejército y el aparato estatal, una lucha que estaba motivada por la promesa de nación y de desarrollo. Vimos también que la insistencia en la promesa del desarrollo (el deseo de justicia social y de resolución histórica) ha permitido a los usibambinos reconstituirse como comunidad, a pesar de toda suerte de divisiones y tensiones. La comunidad como expresión de un anhelo de justicia social fue conceptualizada como una 'imposibilidad constitutiva', es decir como un proyecto de justicia social y de construcción de un común en un contexto de divisiones y competición. Demostramos que el proyecto de construir el común de la comunidad está fundamentado en un trauma 
primordial, que tiene origen en la forma como se logró la re-distribución total de la tierra en los años 70: gracias a una alianza entre comuneros pobres y el ejército peruano contra un grupo de comuneros que había estado monopolizando el acceso a la tierra. Lo que llamamos la (im)posibilidad constitutiva de la comunidad, es decir, de anhelos por justicia social y reparación histórica, es expresada por los comuneros cuando (re)claman - a veces en forma de queja, pero otras como un motivo de orgullo - de que son siervos de la comunidad. Renunciar a la promesa por el desarrollo no solamente significaría traicionar las luchas de sus antepasados, pero también renegar un deseo que les es fundamental.

\section{Referencias}

ARCE, Alberto; LONG, Norman. Anthropology, Development and Modernities: Exploring Discourse, Counter-Tendencies and Violence. London: Routledge, 2000.

DE VRIES, Pieter. Don't compromise your desire for development! A Lacanian/ Deleuzian rethinking of the anti-politics machine. Third World Quarterly, 2007, v. 28, n. 1 , p. 25-43.

DE VRIES, Pieter ; GILVONIO, Manuel. Debating property: property relations and the cultural construction of community in Usibamba, Central Andes of Peru. In: ZOOMERS, Annelies (ed.) Land and sustainable livelihood in Latin America. Amsterdam: Royal Tropical Institute, 2001, p.107-124.

ESCOBAR, Arturo. Encountering Development. The Making and Unmaking of the Third World. Princeton, N.J.: Princeton University Press, 1995.

ESCOBAR, Arturo Territories of Difference. Place, Movements, Life $<$ Redes $>$. Durham: Duke University Press, 2008.

ESCOBAR, Arturo. Latin America at a Crossroads. Cultural Studies, 2010, v. 24, n.1, p.1-65. Parcialmente traducido al español como 'América Latina en la encrucijada: imodernizaciones alternativas, posliberalismo o posdesarrollo?'. In: BRETÓN, Víctor (ed.), Saturno devora a sus hijos. Miradas críticas sobre el desarrollo y sus promesas. Barcelona: Icaria Desarrollo Rural, 2010, p. 33-85.

GILVONIO, Manuel. Construcción Cultural de Comunidad y Migración Internacional en Usibamba. Tesis doctoral Wageningen University, 2009. 
MALLON, Florencia. Peasant and Nation. The Making of Postcolonial Mexico and Perú. Berkeley: University of California Press, 1995.

MIGNOLO, Walter. Coloniality, Subaltern Knowledges and Border Thinking. Local Histories/Global Designs. Princeton, N.J.: Princeton University Press, 2000.

NUIJTEN, Monique; LORENZO, David. 'Né pour être esclave': migration transnationale des bergers d'une comunidad andine. Anthropological Journal of the Canadian Anthropology Society, 2009 a, n. 51, p. 67-80.

NUIJTEN, Monique; LORENZO, David. Ruling by record: the meaning of rights, rules and registration in an Andean Comunidad. Development and Change, 2009 b, v. 40, n.1, p. 81-103.

SANTOS, Boaventura. Beyond Abyssal Thinking. From Global Lines to Ecologies of Knowledges. Disponible en: < http://www.eurozine.com > . Accesado en: 10 jul. 2012.

WALLERSTEIN, Immanuel. The Modern World System: Capitalist Agriculture and the Origins of the European World-Economy in the 16th Century. New York: Academic Press, 1974.

RADOMSKY, Guilherme F. Desenvolvimento, Pós-estruturalismo e Pós-desenvolvimento. A crítica da modernidade e a emergência das modernidades alternativas. Revista Brasileira de Ciencias Sociais, 2011, v. 26, n. 75, p. 149-193.

WALSH, Catherine. Development as buen vivir: institutional arrangements and (de)colonial entanglements. Development, 2010, v. 53, n.1, p. 15-21.

WOLF, Eric. Europe and the People without History. Berkeley: University of California Press, 1982.

ŽIŽEK, Slavoj. Organs without Bodies: On Deleuze and Consequences. London: Routledge, 2003.

ŽIŽEK, Slavoj. A Glance into the Archives of Islam. Disponible en: < http://www. lacan.com/zizarchives.htm >. Accesado en: 10 jul. 2012.

Recebido em: 25/07/2012

Aceite final: 15/10/2012 